\title{
Developing research partnerships to bring change: expe- riences from REACH Trust, Malawi
}

\author{
B. Nhlema Simwaka', S. Theobald ${ }^{1,2}$ G. Mann'2, F. Salaniponi ${ }^{3}$, H. Banda', L. Nyirenda', G. Bongololo', \\ L. Sanudi', P. Nkonjera', W. Sangala ${ }^{4}$, I. Makwiza', S. B. Squire ${ }^{1,2}$
}

\author{
' Research for Equity and Community Health Trust (REACH Trust), Lilongwe \\ ${ }^{2}$ Liverpool School of Tropical Medicine, UK \\ ${ }^{3}$ Malawi National Tuberculosis Control Programme, Lilongwe \\ ${ }^{4}$ Independent consultant, Lilongwe, Malawi
}

Drawing on the experiences of REACH Trust, this paper highlights practical lessons of using research processes and outcomes to promote equity in health policy and practice. The REACH Trust is first introduced. Case studies are then used to highlight how REACH Trust has worked in a participatory manner with key stakeholders at community, national and international levels. In addition to participatory working there are a number of cross-cutting themes

\section{Background}

The Malawi National Tuberculosis Control Programme (NTP) has an excellent record and international reputation for conducting programme-relevant operational research. In 1999 the NTP formed a research collaboration with the Liverpool School of Tropical Medicine and the University of Malawi to expand this operational research base. This collaboration was funded by the Department for International Development (DFID) as the "TB Equity Project,' with the aim of conducting research to promote access to TB care, particularly for the poorest and most vulnerable populations. Under the TB Equity Project, a number of research studies were conducted, showing the impact that gender, poverty and barriers to access to TB care have on TB control. Since 1999 the collaboration has expanded into a programme of research to promote equity in TB, attracting additional core funding from DFID as well as project grants from the World Health Organisation's Special Programme for Tropical Disease Research (TDR), Stop TB Partnership, the Norwegian Heart and Lung Association (LHL) and the Southern African Health Equity Network (EQUINET).

The REACH Trust was legally constituted under Malawi law in 2005 to reflect a widening research portfolio, which has now grown to embrace HIV and malaria as well as TB. In this way staff at REACH Trust have synthesised approaches and concepts generated in TB research to applied research in these other critical diseases of poverty.

\section{REACI Trust Vision Statement}

To be an internationally reeognised leading institution in health equity research in Malawi, working to break the eycle of pover ty and 11 heallh

\section{RIA AH Trust Mission Statement}

To conduct research to promote equity in health, that

- Is close to policy and informed by new developments such as the SWAP

- Is multidisciplinary

- Strengthens capacity at community and national levels and to promote equitable, pro poor, gender sensitive health provision, through

- High quality policy relevant research in diseases of publi hearth and poverty importance, inoliding TB, IIIV an malaria

Malawi Medical Journal: Special Edition on Equity II that facilitate the uptake of research findings which is discussed in turn: (1) multi-disciplinary and multi-method approaches (2) advocating research findings at strategic forums, and (3) the use of strategic frames. In the conclusion it is argued that research has a ritical role to play in responding to the urgent need for the Malawian health sector to develop and act on evidence-based practice in a more gender equitable and pro-poor manner.
Developing multidisciplinary and participatory research capacity

- Building collaborative partnerships

- Using research outputs for dissemination and advocacy

The REACH Trust currently has 32 members of staff and is based at the Community Health Science Unit in Area 3 in Lilongwe. It comprises a multi-disciplinary team with expertise in sociology, clinical sciences, health economics, and development (including participatory approaches) and experience in a number of different aspects of equity and communicable disease. REACH has 12 Trustees who oversee and advise the Trust's activities. As an independent trust, REACH has worked to also develop its institutional base with investments in administrative support and infrastructure, externally audited accounts, and a staff development programme that has provided an opportunity to social science graduates for local postgraduate training.

Using research to promote equity in policy and practice: lessons learned

Core to our philosophy and reflected in our mission statement is the focus on conducting research that is policy-relevant. However, the relationship between policy and practice is not linear or straightforward'; it cannot be assumed that more research means more evidence-based policy, nor that more policy means improved practice. There are substantial obstacles to translating research findings into policy and practice2REACH Trust has found that participatory working at community, national and international levels alike can reap benefits in ensuring that research findings impact on policy and practice. This is followed by an overview of three key inter-related themes that are central to participatory working (1) multidisciplinary and multimethod approaches (2) advocating research findings at strategic forums and (3) 'strategic framing'.

Participatory working at community, national and international levels

The REACH Trust has grown from a research relationship with the National TB Control Programme (NTP) and other partners. Its relationship with the NTP is further strengthened by working under the same roof and having the Director of the NTP as part of the management structure. Furthermore, REACH Trust sits in all NTP strategic management group meetings. This means that 
the two organisations have been able to work together in identifying research gaps, designing and implementing research projects and discussing the implications of research for policy and practice. This strong relationship is illustrated through the following two case studies:

Case Study 1: Translating gendered community needs into practice. worlking with storekeepers

The REACH Trust conducted qualitative and participatory research in poor areas of Lilongwe to map poor wenten and men's pathways to seeking care for tuberculosis: This research wicovered many inter-related baniers in accessing formal TB care services. These findings were fed back to community menbers using participatory approaches, including drama. In Whe ensuing discussion community members proposed a vom? munity-based intervention to shorien the pathway to TB servic. es. They suggested that storekeepers and key community members should be equipped wilh advisory and health prometion skills since they are first contacts in care seeking being easily decessible at the community level.

The proposal was then presented to providers and policy mak ors at distriet and nationgl le vel through different forums such as cenferenees and management meetings for the NTP. The com munity members proposed that addressing bariers should not be limited to tuberculosis, but should also inelude nalaria because it is a major healh problem for children. as well as women and men. Wothers and female carers in particular face challenges in seeking care for chitaren with symptoms indica. live of nalara, as caring is constructed as a largely female role. consequently discussions were also held between the National Malaria Control Programine and the National Tuberculosis Programme, A joint malaria-TB intervention was developed to address issues of improper advice on home management of non. serious malaria and delay in seeking care for wberculosis. The infervention involves training storekecpers, volunteers and com munity membeis in advisory and refermal skills, health promom tion and referral skills. Early evaluations show lhat these interventions are increasing women and men's ability to uptake TB and malaria services.

\section{Case Study 2. Integrating gender equity and concerns into} NIP core activities

Through advocacy tron the REACH Trust. the NTP has strengthened its institutional capacity through creating the post of Gender and Equity Officer. The post holder is expected to sustain collaboration, analysis and disscmination of gender - disaggregated data for advocacy. The NTP integrated equity and gender within their tive-year development plan. This includ ed. for exumple, the provision of funding for community based initiatives to address biniers to and costs of accessing care. REACH Trust has produced a policy briefing on the how to' of de veloping partuerships with community or ganisations or stric tures (such as store keepers, home based care groups. etc) to entrance case detection for TB in Malawi. This policy briefing his been cireulated to all District Heall Offieers to inform the process of developing District Timplementation Plans (1DIPs).

The case studies show how working closely with the NTP has created an opportunity for translating research findings into interventions that meet the needs of poor women and men, as well as developing strategies to institutionalise and sustain a gender equity approach in NTP's core activities.

REACH Trust also works at a regional level and sits on the Steering Committee of the Southern African Health Equity Network - EQUINET. This has enabled it to feed Malawi perspectives into this regional advocacy network. This will be con- solidated in 2006 with the development of a Malawi equity analysis, which will be led by the REACH Trust in collaboration with the Malawi Health Equity Network (MHEN), and the Equity and Access Sub Group. Through MHEN, REACH has been able to disseminate research findings and advocate for propoor policies at parliamentary fora. The following box summarises the process and focus of the country equity analysis.

\section{A country equity analysis}

A country equity analysis is more than a report: It is a process of networking all country persomnd working on healli eculity. neluding, hut not limited to. Those working within FOULNTI themes and processes. It feeds cotmiry experience and evidence and provides da oppontunity to draw together jerspectives. evi dence, experiences and views, to strengthen dialogue and net working and to bulld shared learning and analysis within countries and within the region on eguty priorities identified at conntry level. Ir dims to assess. where things are at he country level on a range of priorily areas of heal hequity and to propose options for ddilressing hem.

The cointry equity andy sis in 2006 will be guided by the area of focus of the reglonal equity analysis, 1 e. on building com. prehensive, universal and integrated national health sys. lems, particularly exploring:

1. Bulding people-1ed people-centered health systems that organite, empower, value and entitle people:

1. Promoting ncreased fair, sustainable and equitable financing for lealth ar national, regional and global levels in order to secure the univer sal right to health:

11. Insuring adequate we1-trained, equitably distributed and motivated hoalth wo kers:

iv. Advocting for tair global polley (just trade reversing unfair flows of resources) with national and regional policy lexibility to exercise polictes that improve healh. Activities and ouputs will include the following:

1. A list of equity actors in country shared within the country and in the EQUINET database

1. A list of country equity priorities and a reference list of published work done 10 date un the e with any electronic doctments fed into the LQUINET anmotated bibllogtaphy database.

hi. A meeting held for country equiy actors

11. A country eguity analysis tepont providing evidence, experiences, positive examples, case studies, voices trom civil society (including real stories from community life) ministers and partianen, govermment comnitment. meeting resolutions, and photographs and graphics:

For further information on this please contact Mastings Banda at the REACH Trust in Lilongwe.

This equity analysis will provide an opportunity for further networking and policy advocacy at community, national and regional levels.

REACH has also worked in collaboration with core partners at an international level. It set up a website (www.tb-poverty.org) which has a searchable database of publications relating to $\mathrm{TB}$ and poverty, case studies and examples of 'evidence based' best practice in pro-poor approaches from Africa REACH members have also played a role in feeding Malawian experience into the WHO International Guidelines to Addressing Poverty in TB Control: Options for the National TB Control Programmes ${ }^{5}$ and are members of the TB \& Poverty Core Group of the Global Partnership to STOP TB (http://www.stoptb.org/tbandpoverty/)

These activities have begun a paradigm shift in TB Control with an increasing understanding that pro-poor approaches are important for equitable, efficient and sustainable TB Control Programmes. This approach has been highlighted in a recent editorial $^{8}$ and forthcoming commentary ${ }^{9}$ in the Lancet. The Secretariat for TB and Poverty will continue its activities in Malawi Medical Journal: Special Edition on Equity II 
2006/7 and will be hosted, through an international partnership, by REACH Trust, the Liverpool School of Tropical Medicine, UK and KNCV, who have their head offices in the Netherlands. REACH Trust anticipates that this joint hosting will consolidate its partnerships with these other players, maximising the benefits emanating from their different comparative advantages to continue to promote the need for pro-poor approaches in TB Control.

\section{Multidisciplinary and multi-method approaches}

Health research that contributes to change may require more multidisciplinary approaches and methodological pluralism 5 . REACH Trust has used multiple methods including quantitative approaches (questionnaires, simulated client surveys, gender analysis of pre-existing routinely collected health information) and qualitative approaches (focus group discussions, in-depth critical incidence interviews, key informant interviews and participant observation). REACH Trust has found that presenting findings from multidisciplinary approaches and multiple methods can be strategic in advocating for change. This comes down to both personal preference (some policy makers prefer and are more convinced by quantitative methods than qualitative methods and vice versa), but also creates opportunities to present a holistic picture. For example, analysis of questionnaires can produce statistical significance on the numbers of poor women and men failing to access services; whilst the qualitative findings can help contextually explain these figures by describing in poor women and men's own words the barriers, challenges and obstacles they face in service access. Qualitative testimonies can be a powerful tool in highlighting gendered disparities in health experiences and they reveal in-depth information about cases or patients.

\section{Advocating research findings at strategic fora}

In collaboration with the Lighthouse, REACH Trust conducted in-depth qualitative work on barriers to access and adherence to ART. This was conducted in 2003/4 when ART was provided at cost, and at the time that there were many policy discussions on how to scale up ART across Malawi. At a number of key policy discussion groups and strategic fora, REACH staff presented findings showing that cost constituted the key barrier to access to ART and that this was gendered, with women in particular struggling to meet the costs required ${ }^{10}$. These findings fed into discussion at the Ministry of Health and were arguably influential in shaping the newest Malawian policy. This includes ART drugs provided free, a particular emphasis on health promotion strategies that are geared towards poor and vulnerable groups and the promotion of harmonised concurrent provision through the private sector. REACH Trust has also advocated for sex disaggregated data collection by the HIV unit in the Ministry of Health, following the production of the Makwiza et al. report on "Monitoring Equity and Health Systems in the provision of ART ${ }^{10}, "$

\section{'Strategic framing' - adopting different languages or dis- courses to discuss gendered research findings}

It can be strategic to situate research findings within different languages or discourses depending on the audience. This has been referred to as 'strategic framing' and has been discussed in the gender literature ${ }^{11,12}$. As individuals, we may believe in and work within a gender equity and rights discourse, i.e. poor women have a right to accessible and quality TB services. But we may choose to situate our research findings within instrumental or technical arguments that prioritise efficiency or sustainability, as these may be more accessible to policy makers than a discussion of gender and rights. It could, for example, be argued that if TB services are inaccessible or unacceptable to poor women, TB programmes will not be cost-effective, nor will they be able to meet their case detection and cure rates targets. With negative repercussions for the community from a large number of unidentified, untreated, infectious TB cases: this clearly threatens the efficiency and sustainability of the entire TB programme.

\section{Conclusion}

Research is not a passport to policy ${ }^{5}$. For research findings to inform policy and practice there is a need for well thought out strategies and approaches. Key to this is the importance of developing sustained and responsive relationships with policy makers. These relationships enhance the ownership of the research process and hence the likelihood of policy makers adapting policy and practice in the light of research findings. Other strategies to promote uptake of research findings include sustained advocacy at policy fora and technical working groups that uses multiple methods (numbers and voices) to illustrate the main issues and deploy different strategic frames - equity, gendered rights, efficiency, sustainability - depending on the audience. There is a clear need for ongoing discussion and action to address the poor's health needs in Malawi. As researchers there is a need to continue to proactively search for opportunities to use our research to promote equitable policy and practice, so that health services better meet the needs of poor women, men, girls and boys.

\section{References}

1. Groenewald C. Transiating research into policy. 2005 Availablefrom:http://population.pwv.gov.za/ConSemEvents/ Documents/TranslatingResearchIntoPolicy $\% 20$ \%20Cornie\%20Groenewald doc. Accessed: 28/06/2005.

2. US Department of Health and Human Services. Translating research into practice (TRIP) - II. Public Health Service. 2000. Available from: www.ahrq.gov/research/trip2fac.htm on 28/06/2005.

3. Nhlema Simwaka B, Nkhonjera P, Sanudi L, Gondwe M, Bello G, Chimzizi R, Theobold S. The Malawi National Tuberculosis Programme: An Equity Analysis. Malawi Medical Journal. 2006; 18 (1):

4. REACH Trust. Policy Paper. 2005

5. Davis P, Howden-Chapman P. Translating research findings into health policy. Social Science and Medicine. 1996; 43: $865-72$.

6. World Health Organization. Addressing poverty in TB control: options for National TB Control Programmes. Geneva: World Health Organization:2005. Available from:

http://www.who.int/tb/publications/2005/en/index.html.

7. TB \& Poverty Core Group of the Global Partnership to STOP TB. Available from: http://www.stoptb.org/tbandpoverty/.

8. Editorial. Táckling poverty in tuberculosis control. Lancet 2005: 366: 2063

9. Squire SB, Obasi A, Nhelma Simwaka B. The Global Plan to STOP TB: unique opportunities for addressing poverty and for the Millennium Development Goals. Lancet 2006 (in press)

10. Makwiza I, Nyirenda L, Bongololo G, Loewenson R, Theobald, $S$. Monitoring equity and health systems in the provision of Anti-retroviral Therapy (ART): Malawi country report. EQUINET Discussion Paper No. 24. Harare: EQUINET; 2005.

11. Theobald S, Tolhurst R, Elsey H, Standing H. Engendering the bureaucracy? Challenges and opportunities for mainstreaming gender in Ministries of Health under Sector Wide Approaches. Health Policy and Planning. 2005; 20: 141-149.

12. Pollack $M$, Hafner-Burton. Mainstreaming gender in the European Union. J Eur Public Policy. 2000; 7: 432-456. 